\title{
Work design and its Relation to Productivity among Staff Nurses
}

\author{
Heba A. Ali ${ }^{1}$, Sanaa M. Safan ${ }^{2}$ and Sohair M.Mabrouk ${ }^{3}$ \\ ${ }^{1}$ B.Sc. Nursing Science, ${ }^{2}$ Assistant Professor of Nursing Administration, \\ ${ }^{3}$ Assistant Professor of Nursing Administration, Faculty of Nursing, Menoufia \\ University
}

Nursing productivity refers to effectiveness of nursing care which relates to this quality and appropriateness and efficiency of care. The purpose of this study was to investigate work design and its relation to productivity among staff nurses. . Design; a descriptive corelational research design. A convenient sample of 400 staff nurses was selected to carry out this study. Setting; this study was conducted at Menoufia University Hospital at Shebin El-Kom , Menoufia Governorate, Egypt. Two instruments were used to conduct the study for work design questionnaire and productivity questionnaire. Results: there was a positive statistically significant correlation between studied staff nurses' work design and productivity. The majority of studied staff nurses had moderate levels of work design characters; the first ranking with the highest mean score was social characteristics while the last ranking was task character. Moreover, more than two third of studied staff nurses had low levels of productivity, nearly one fifth of them had moderate level of productivity. Otherwise, the minority of them had high levels productivity. Additionally, the first ranking of productivity was work organization and the last ranking with the lowest mean score of productivity was working conditions. Conclusion: there was positive highly statistically significant correlation between work design and staff nurses' productivity. Recommendation; continuing education programs and training courses for nurse manager and their staff about work design character and productivity.

Key words: Work design, productivity, staff nurses

\section{Introduction:}

Work design is essential to the success and efficiency of the work and creates clarity. Clarity is one of the biggest reasons every role within work and should be defined via work characteristics. One of the biggest motivating factors is clarity of the nurses' role. Nurses know what they are supposed to do and how to do it. There is no ambiguity there is no anxiety (Asensio, 2012). The main purpose of work design is to create a job specification and bring best performance abilities. It is vital to find out, how the nurses view their work, how best their jobs are designed to bring about well-being of the organization and them. For this purpose, it is vital for them to be motivated by decision involved and stay aligned with the objectives of the organization. Moreover, the work design has a significant impact upon increases nurses' productivity itself in various forms as improvements in the quality and quantity of goods and services, reduction in the operation costs and in the turnover and training costs. The increase in the nurses' motivation can be achieved through increase in job satisfaction (Frederick, 2015).

The aim of a work design is to improve job satisfaction, to improve quality and to reduce nurses problems (e.g., grievances, absenteeism), and it plays a vital role as it affects the productivity of nurses and organizations. It helps to adjustment with the changes in the workplace. The end goal is reducing dissatisfaction, enhancing motivation and nurses engagement at the workplace. Work design is defined as a systematic organization of work-related tasks, responsibilities, functions and duties. It essentially involves integrating job responsibilities or content and certain qualifications that are required to perform 
the same. It outlines the job responsibilities very clearly and also helps in attracting the right candidates to the right job. Further it also makes the job look interesting and specialized. There are many benefits of a good work design as employee input, employee training, work / rest schedules, adjustments. There are various methods or approaches to do this as human approach, engineering approach, the job characteristics approach (Saber, 2019).

The job characteristics approach was there is a direct relationship between job satisfaction and rewards. In this approach the nurses will be their productive best and committed when they are rewarded appropriately for their work. It laid down five core dimensions that can be used to describe any job-skill variety, task identity, task significance, autonomy and feedback. There are a number of issues while designing the work in organizations. Issues like - telecommuting/work from home, job sharing, flexi-working hours, alternative work-patterns and techno stress. The various factors that affect work design can classified under three major heads organizational factors, environmental factors and behavioral factors. (Bacon, 2015).

Nursing productivity is defined as converting resources (input) into products and services efficiently, effectively and with optimum utilization of human capital and physical resource for the benefits of society, the economy and the environment. Productivity is the relationship between the output generated from a system and the input provided to create this output. Productivity is doing more with less effort (Abd Allah, 2011). Nursing productivity refers to effectiveness of nursing care which relates to this quality and appropriateness and efficiency of care (Olsen, 2017).

Productivity has become a day - to - day concern for managers because it indicates the overall efficiency of their organization. Also, it is the key that
- opens the door to management action and reward program (Jacksonvilla, 2014). Productivity gains meai 1 a. higher standard of living, shorter working hours, longer vacation, bigger paychecks and more fringe benefits. It is very important to know all about productivity to reach the maximum quality in our health organization. The area of productivity measurement remains somewhat ambiguous in many industries, not just health care. In health care the difficulties are compounded by problems related to quality and output measurement. Nursing productivity refers to effectiveness of nursing care which relates to this quality and appropriateness and efficiency of care (Olsen, 2017).

\section{Purpose}

The purpose of this study is to investigate work design and its relation to productivity among staff nurses.

The following research questions were developed to conduct this study:

- What is the actual characteristics work design?

- What are the levels of nursing productivity?

- Is there a relation between work design and productivity among studied staff nurses?

\section{Methods}

1. Research Design: A descriptive correlational research design was used in the present study to achieve the purpose of the study.

2. Research Setting: This study was conducted in different units and departments at the units of Menoufia University hospitals. They were divided into two categories: Critical care units which include Emergency, Operative rooms, Adult ICU, Pediatric ICU, and Hemodialysis Unit. Inpatient units include the following units: Medical, Surgical, Obstetrics and Gynecology, 
Orthopedics and Oncology departments.

3. Sample: A convenient sample size was calculated utilizing G Power program, with a power of 0.95 , alpha of 0.01 , and a medium effect size. The total number of staff nurse was 1200 , the minimum sample size required for Pearson correlation analysis was 367 respondents. Sample size was determined by using solving formula to assess the sample size of staff nurses; $\mathrm{n}=\mathrm{N} \backslash 1+(\mathrm{N}$ e 2$)$. Where $(\mathrm{n})=$ sample size, $(\mathrm{N})=$ is the total number of staff's nurse $(1200)$. (e) $=$ error tolerance (.05), $1=$ a constant value. Sample size of staff nurse $=1200 \backslash(1200 \times(.05) 2)$ $=400$ the total.

4. Instruments: two instruments were utilized for data collection:

Instrument one: Work design questionnaire: It consists of two parts. Part I: Demographic characteristics such as age, educational level, work units and departments, years of experiences, and distance from home to work. Part II Work design questionnaire. It was adopted by Frederick (2015) and modified by the investigator. It was used to determine the characteristics of actual work design. It consists of four dimensions: task characteristics 12 items such as my job allow me to make my own decisions about how to schedule my work...etc., knowledge characteristics 8 items such as my job requires that I only do one task or activity at a time...etc., social characteristics 10 items such as I have the opportunity to develop close professional friendships in my job...etc. and work context 9 items such as the seating arrangements on the job are adequate (e $\mathrm{g}$ , ample opportunities to sit, comfortable chairs) ...etc. Reliability tested by Cronbach's Alpha test, was equal 0.78.

Scoring system of instrument

one:
Three - Point's Likert scale type will be used for each statement in the second part second part as follows:

\begin{tabular}{|l|l|}
\hline Disagree & 1 \\
\hline Uncertain & 2 \\
\hline Agree & 3 \\
\hline
\end{tabular}

The scores of the items were summed up and total divided by the number of the items, giving a mean score for the part. These scores were converted into a percent score. The domain was considered to be a high score indicate a high level of nurse's work design character, if the score percent was $75 \%$ or more, if the score percent was $60 \%$ to $74 \%$ a moderate level is expected, if the score is less than $60 \%$ a low level is expected.

Instrument two: Productivity questionnaire: It is used to determine the level of productivity elicited by nurses. The responses are "Yes" or" No". It contains under eighteen dimensions: Aim 6 items, working conditions 3 items, work engagement 5 items, work motivation 6 items, work organization 2 items, Equipment and supplies 5 items, quality of nursing services 7 items, Employee growth (nurses) 4 items, problem solving and decision making 4 items. Social relation 4 items, sick leave 5 items, work effectiveness 3 items, development and advancement 3 items, physical work environment 6 items, waste disposal 4 items, initiative 3 items, new skills 3 items and work habits 3 items. Reliability tested by Cronbach's Alpha test, was equal 0.95.

\section{Scoring system of instrument}

\section{two:}

Productivity questionnaire instrument: The responses was (Yes) or (No) question. Each question was assigned a score of (1) if the answer Yes and (0) if the answer No (Abd Allah, 2011). A high level of productivity is considered if the total score ranges from $75 \%$ to $100 \%$. A moderate level of productivity is considered if the total score ranges from $60 \%$ to 74 . If the 
total level was less than $60 \%$ this indicates low level of productivity.

Validity: Five experts were selected to test the content and face validity of the instruments. The panel included five experts from Nursing Administration Department (3 professors and 2 assistant professors) at Faculty of Nursing Menoufia and Tanta University. No necessary modifications were required.

\section{Pilot study:}

It was carried out on $10 \%$ of the total sample 40 nurses after the instruments were developed and before starting the data collection to ascertain the clarity, relevance, applicability of the study instruments and to determine the obstacles that may be encountered during data collection. Pilot study sample was included in the studied sample.

Ethical Considerations: Approval of the Faculty of Nursing Ethical Research Committee was obtained before conducting the study. A written from consent was obtained from the sample after explaining the purpose, nature, time of conducting the study, potential benefits of the study and how data were collected. The respondents were assured that the data will be treated as strictly confidential; furthermore, the respondents' anonymity was maintained as they were not required to mention their names.

\section{Procedure:}

An official permission to carry out the study was obtained from the directors of Menoufia University Hospital after submitting an official letter from the Dean of nursing Faculty.

Data was collected over three months started from 8th of December 2019 to the end of January, 2020 after securing necessary permission.

Before beginning to collect data from the study subjects the investigator introduced her to them, explained the purpose of the study, and informed them that their information would be treated confidentially and will be used only for the purpose of the research. Additionally, each participant was notified about the right to accept or refuse to participate in the study.

\section{Data Analysis}

The collected data were organized, tabulated and statistically analyzed using SPSS version 20 created on IBM compatible computer. For numerical values the mean and standard deviations were calculated. Chi square test was used to detect the statistical differences between variables. $\mathrm{T}$ test was used to compare between two means of parametric data. Person correlation test was done to study the correlation between one qualitative variable and one quantitative variable or two quantitative variables of not normally distributed data the statistical difference was considered significant if $\mathrm{P}<0.05$.

\section{Results :}

Table1: Shows distribution of studied staff nurses regarding their socio demographic characteristics. As shown from this table the highest percent of nurses $(54.5 \%)$ had $<30$ years old, also the highest percentage of the studied staff nurse had diploma (56\%). Regarding, Work units and department, the highest percentage of staff nurses had work at Critical care units $(71 \%)$. Regarding years of experience, the highest per cent of studied staff nurses $(35 \%)$ was had $1-<5$ years of experience degree in nursing. Additionally, about third of them had suitable distance from their work.

Table (2) and Figure (1): Illustrate ranking with mean score of work design characters as reported by studied staff nurses. As notices from the table, the totals mean score of work design was (84.28 \pm 12.54$)$. Additionally, it showed that the first ranking with the highest mean score was $(24.55 \pm 3.86)$ related to social characteristics while the last 
ranking with the lowest mean score was $(20.33 \pm 3.8)$ related to task character.

Table (3) and Figure (2): Displays ranking with mean score regarding total productivity as suggested by studied staff nurses. As notices from the table, the totals mean score related productivity was (42.9 \pm 9.38$)$. Additionally, it showed that the first ranking was $(1.67 \pm 0.69)$ related to work organization. While the last ranking with the lowest mean score was

Table (1): Distribution of studied staff nurses regarding their social characteristics $(n=400)$ :

\begin{tabular}{|c|c|c|}
\hline Variables & No & $\%$ \\
\hline \multicolumn{3}{|l|}{ Age } \\
\hline$<30$ years & 218 & 54.50 \\
\hline $30-40$ years & 156 & 39.00 \\
\hline$\geq 40$ years & 26 & 6.50 \\
\hline \multicolumn{3}{|l|}{ Sex } \\
\hline Male & 192 & 48 \\
\hline Female & 208 & 52 \\
\hline Educational qualification & & \\
\hline \multicolumn{3}{|l|}{ Nursing Bachelor } \\
\hline - $\quad$ Associated degree & 104 & 26.00 \\
\hline Nursing Diploma & 224 & 56.00 \\
\hline \multicolumn{3}{|l|}{ Work units and department } \\
\hline \multicolumn{3}{|l|}{ I- Critical care units: } \\
\hline Emergency department & 30 & 7.50 \\
\hline Operating $\operatorname{room}(\mathrm{OR})$ & 54 & 13.50 \\
\hline Adult Intensive Care unit & 76 & 19.00 \\
\hline Pediatric Intensive Care unit & 94 & 23.50 \\
\hline Hemodialysis Unit & 30 & 7.50 \\
\hline 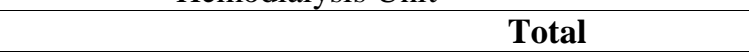 & 284 & 71.00 \\
\hline \multicolumn{3}{|l|}{ II-Inpatient department: } \\
\hline - $\quad$ Medical department & 62 & 15.50 \\
\hline - $\quad$ Surgical department & 2 & 0.50 \\
\hline - Obstetrics and Gynecology department & 20 & 5.00 \\
\hline - $\quad$ Orthopedics department & 18 & 4.5 \\
\hline - $\quad$ Oncology department & 14 & 3.5 \\
\hline 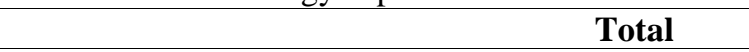 & 116 & 29.00 \\
\hline \multicolumn{3}{|l|}{ Years of experience } \\
\hline - $<1$ year & 2 & 0.50 \\
\hline - $1-<5$ & 140 & 35.00 \\
\hline - $5-<10$ & 132 & 33.00 \\
\hline - $10-<20$ & 100 & 25.00 \\
\hline - $\quad \geq 20$ & 26 & 6.50 \\
\hline \multicolumn{3}{|l|}{ The distance from your home to work } \\
\hline • Near & 92 & 23.00 \\
\hline - Suitable & 226 & 56.50 \\
\hline - Far & 82 & 20.50 \\
\hline
\end{tabular}

Table (2): Ranking with mean score of work design items as reported by studied staff nurses $(n=400)$ : 
Work design and its Relation to Productivity among Staff Nurses

\begin{tabular}{|l|c|c|c|c|c|}
\hline \multicolumn{1}{|c|}{ Work design items } & Minimum & Maximum & Mean \pm SD & Mean Percent \% & Ranking \\
\hline Task characteristics & 12.00 & 34.00 & $20.33 \pm 3.81$ & 56.46 & 4 \\
\hline Knowledge characteristics & 8.00 & 24.00 & $18.94 \pm 3.94$ & 78.9 & 2 \\
\hline Social characteristics & 17.00 & 30.00 & $24.55 \pm 3.86$ & 81.82 & 1 \\
\hline Work context & 12.00 & 27.00 & $20.47 \pm 4.10$ & 75.82 & 3 \\
\hline Total work design & $\mathbf{5 5 . 0 0}$ & $\mathbf{1 1 0 . 0 0}$ & $\mathbf{8 4 . 2 8} \pm \mathbf{1 2 . 5 4}$ & $\mathbf{8 4 . 2 8}$ & - \\
\hline
\end{tabular}

SD: Standard deviation

Figure (1): Ranking with Mean Score Regarding Work Design Characters as Reported by Studied Staff Nurses

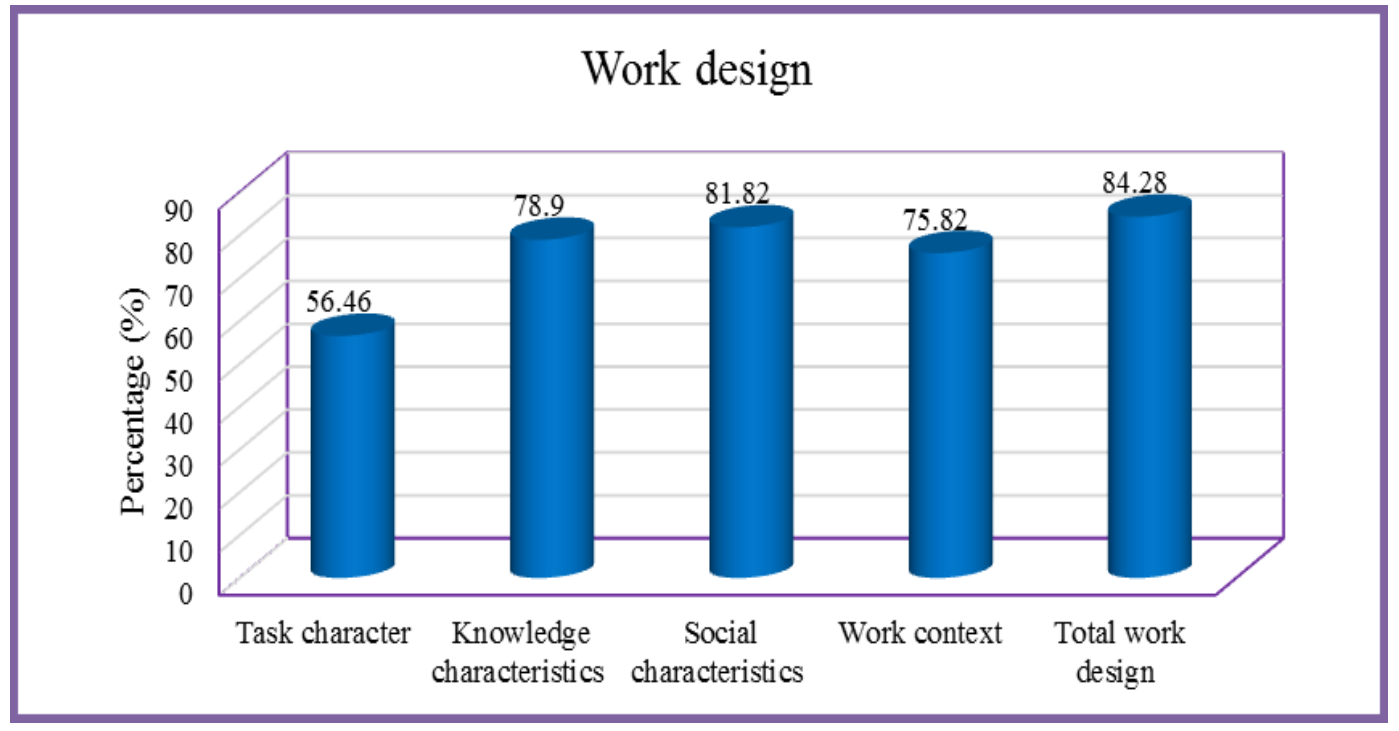

Table (3): Ranking with mean score of productivity items as reported by studied staff nurses $(n=400)$.

\begin{tabular}{|l|c|c|c|c|c|}
\hline \multicolumn{1}{|c|}{ Productivity items } & Mini. & Max. & Mean \pm SD & $\begin{array}{c}\text { Mean Percent } \\
\%\end{array}$ & Ranking \\
\hline Get the aim & 1.00 & 6.00 & $3.92 \pm 1.52$ & 65.33 & 6 \\
\hline Working conditions & 0.00 & 3.00 & $1.18 \pm 0.85$ & 39.33 & 18 \\
\hline Work engagement & 0.00 & 4.00 & $2.49 \pm 1.04$ & 49.9 & 12 \\
\hline Work motivation & 0.00 & 6.00 & $2.58 \pm 1.84$ & 43.08 & 17 \\
\hline Work organization & 0.00 & 2.00 & $1.67 \pm 0.69$ & 83.75 & 1 \\
\hline Equipment and supplies & 0.00 & 5.00 & $2.42 \pm 1.44$ & 48.3 & 13 \\
\hline Quality of services nursing & 0.00 & 7.00 & $3.55 \pm 2.34$ & 50.64 & 11 \\
\hline Employee growth (nurses) & 0.00 & 4.00 & $2.06 \pm 1.05$ & 51.63 & 10 \\
\hline Problem solving and decision making & 0.00 & 3.00 & $1.31 \pm 1.02$ & 43.67 & 15 \\
\hline
\end{tabular}


Work design and its Relation to Productivity among Staff Nurses

\begin{tabular}{|l|c|c|c|c|c|}
\hline Social relations & 0.00 & 4.00 & $2.60 \pm 1.61$ & 65.00 & 7 \\
\hline Sick leave & 0.00 & 5.00 & $2.87 \pm 1.65$ & 57.4 & 9 \\
\hline Work effectiveness & 0.00 & 3.00 & $1.97 \pm 1.03$ & 65.83 & 5 \\
\hline Development and advancement & 0.00 & 3.00 & $1.30 \pm 1.02$ & 43.33 & 16 \\
\hline Physical work environment & 1.00 & 6.00 & $3.82 \pm 1.75$ & 63.67 & 8 \\
\hline Waste disposal & 0.00 & 4.00 & $3.30 \pm 1.19$ & 82.5 & 2 \\
\hline Initiative & 0.00 & 3.00 & $1.42 \pm 1.13$ & 47.17 & 14 \\
\hline New skills & 0.00 & 3.00 & $2.19 \pm 0.89$ & 73.17 & 4 \\
\hline Work habits & 0.00 & 3.00 & $2.26 \pm 0.84$ & 75.33 & 3 \\
\hline Total productivity & $\mathbf{2 4 . 0 0}$ & $\mathbf{6 5 . 0 0}$ & $\mathbf{4 2 . 9 \pm 9 . 3 8}$ & $\mathbf{4 2 . 9}$ & - \\
\hline
\end{tabular}

SD: Standard deviation

Figure (2): Ranking with Mean Score Regarding Productivity as Reported by Studied Staff Nurses.

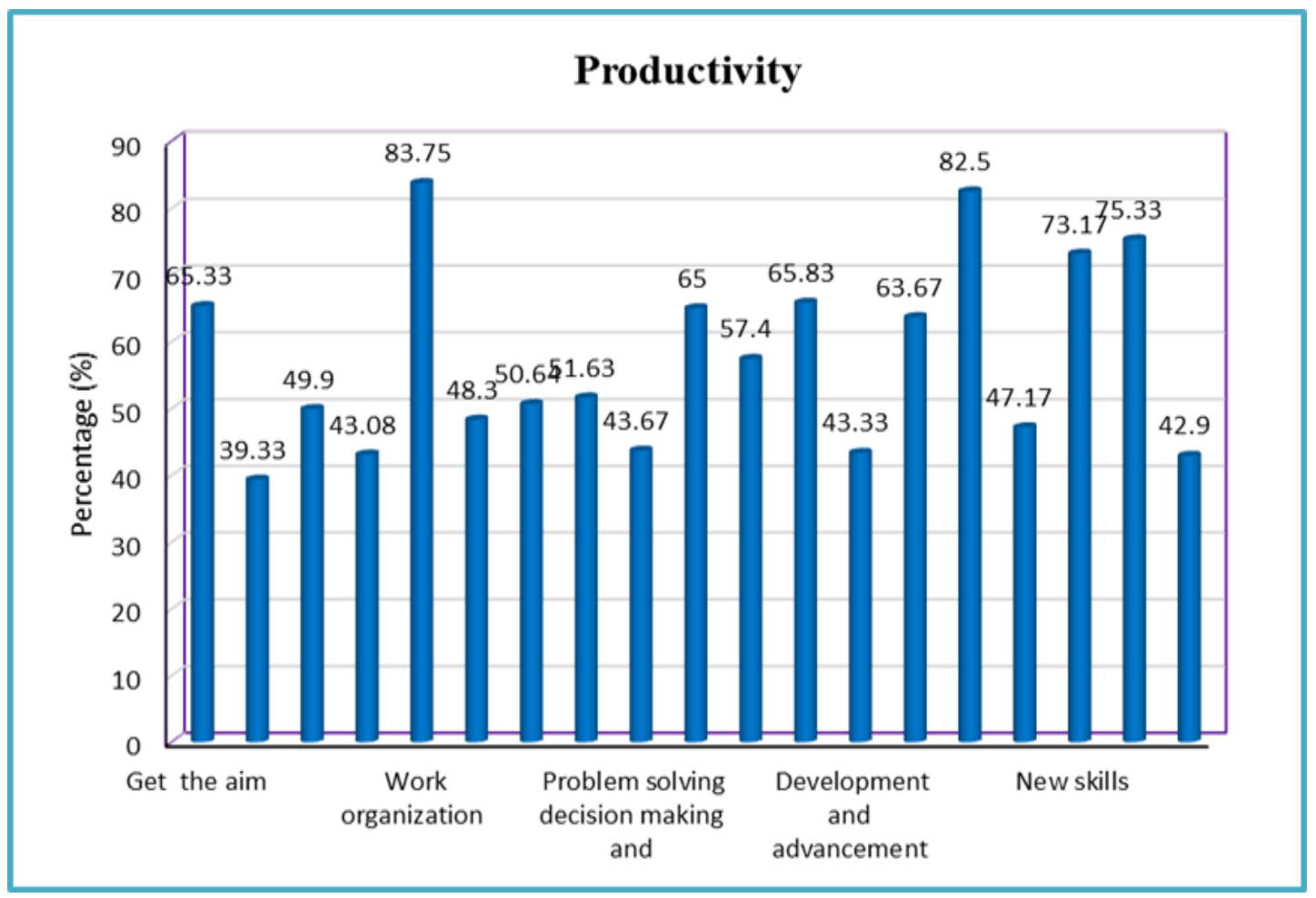

Table (4): Correlation between work design and productivity among studied staff nurses.

\begin{tabular}{|l|c|c|}
\hline \multirow{2}{*}{ Study variables } & \multicolumn{2}{|c|}{ Work design } \\
\cline { 2 - 3 } & R & p. values \\
\hline Productivity & 0.345 & $0.000^{* * *}$ \\
\hline
\end{tabular}

$* *=$ highly significant 
Figure (3): Correlation between work design, and productivity

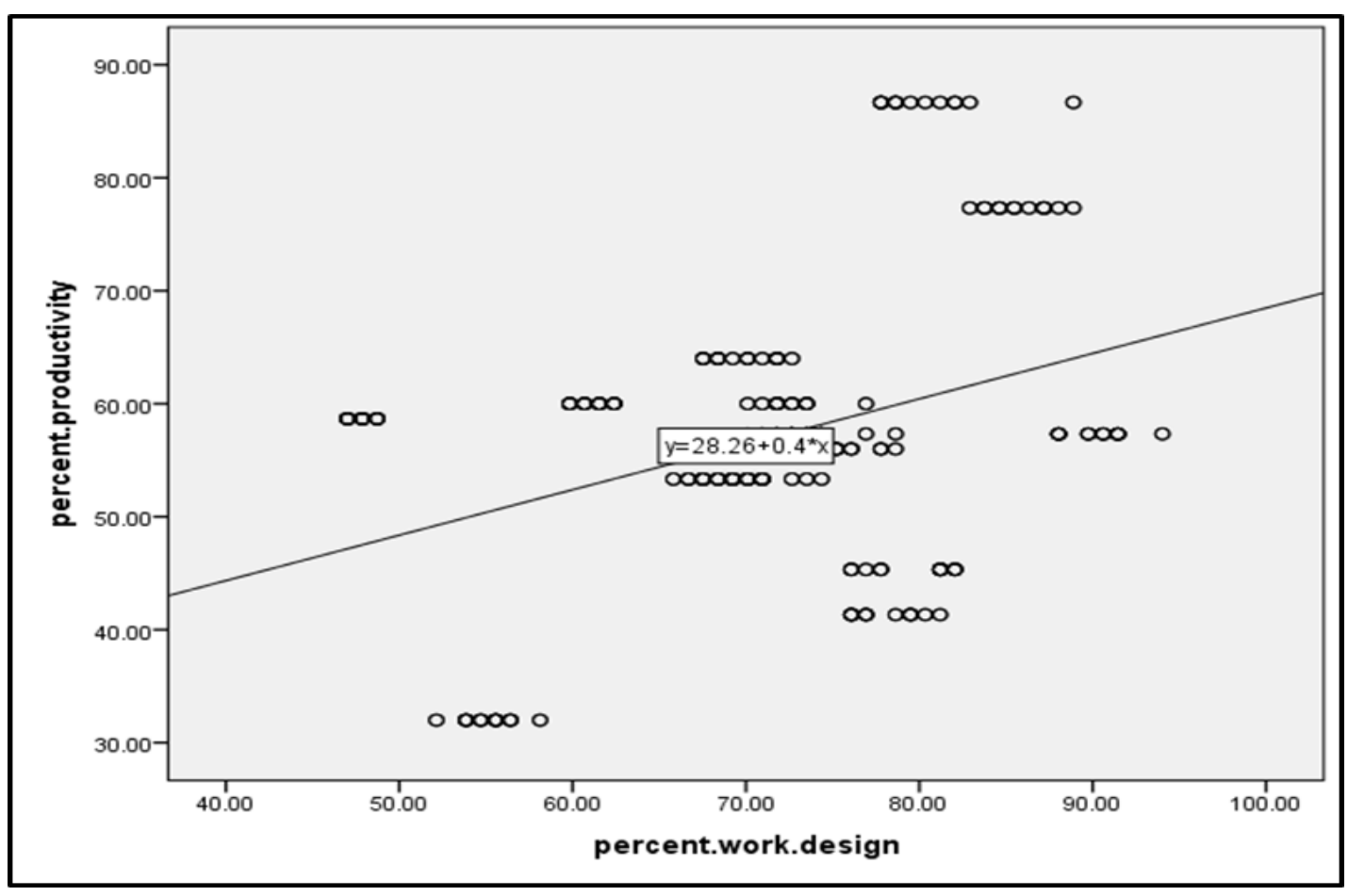

\section{Discussion}

Work design is considered as a core function of human resource management and it is related to the specification of contents, methods and relationship of jobs in order to satisfy professional , technological and organizational requirements as well as the social and personal requirements of the job holder .Nursing productivity refers to effectiveness of nursing care which relates to this quality and appropriateness and efficiency of care (Latif, 2018). Designated work environment help in eliminating the unnecessary care, time waste, organizing nursing care and arranging nursing procedures that affect directly on nurses productivity in which gains shorter working hours, and make nursing time more benefits. (Morgeson, 2019).

Regarding ranking with mean score of work design items, the results of the present study showed that the most common predictors for work design were social characteristics while knowledge characteristics were the least predictor. From the investigator point of view this is might be due to social character constitutes the highest mean percentage due to the nature of nurses job requires to work closely with other, requires a lot of cooperative work with other people thus job depends on the work of many different people for its completion.This was consistent with a study conducted by Rushdy \& Morsy, (2016). It was revealed that one of the most common independent predictors of the nurse manager's task characteristics scores were their scores of social characteristics. Above all, they revealed that knowledge characteristics were the most common predictor.

In the light of continued large numbers of poor-quality jobs, Parker, (2014) clarified that attention must also be given to influencing practices and policy to promote the effective implementation of enriched work designs. Nevertheless, current and future work-based challenges mean that designing work for motivation is necessary but insufficient. Also, Yusof, (2012) demonstrated that, work design characteristics was developed as a common organizational diagnostic tool for 
work characteristics; thus, it can be employing in any fields to assess the nature of work or to design and restructure jobs (Morgeson, 2019). The measure consists of three major characteristics of work design which are the motivational characteristics, social characteristics and work context characteristics (Humphrey, 2007).

Regarding productivity, the findings of our result revealed that the first ranking was related to work organization, from the investigator point of view, this is might be due to designated, organized, well equipped work environment help to be more productive and worked hours divided into shifts made a chance to work overtime for extra paid hours. While the last ranking was related to working conditions, from the investigator point of view, this is might be due to nursing shortage, and had not time to take rest.

This finding agreed with Aithal \& PM, (2016) who demonstrated that, optimizing human productivity is a challenging process for the organization, and this process involves getting the best performance from employees within the organizational constraints. Optimizing Human Performance is used in all organization functions to improve individual and group output, reliability, and productivity. Nurses' growth and development towards higher levels of competency, creativity and fulfilment are encouraged and supported because people are the central resource in any organization. The most successful optimizing human productivity models have five key elements (Baron et al., 2008). Many researchers have tried to optimize productivity using different strategies (Shaw, 2007) including motivation of employees, privatization of organizations, optimizing risks and optimizing rewards and its measurement (Cascio \& Boudreau, 2014).

Also, the study which was performed by Ali, Ali, \& Adan (2013) revealed that the two variables of working condition and employee productivity in manufacturing companies in Mogadishu Somalia are positively correlated. Overall study showed that all indicators of job working condition in terms of working hours, and workload are significantly correlated to all indicators of employee productivity at level of significance of 0.276 with a significant of 0.001 . After looking all the findings it's clear that working conditions is directly affected by employee productivity these two variables have positive relations in terms of working hours and week negative relations in terms of workload so effective working hours will ultimately increase the employee's productivity.

To link the previous studies, a study by Ali, Ali, \& Adan (2013) who found that working conditions have both positive and negative impact on productivity, while, Bacon, 2015 states that in organizations where employees are exposed to stressful working conditions, productivity are negatively influenced and that there is a negative impact on the delivery of service. On the other hand, if working conditions are good, productivity increase and there is a positive impact on the delivery of service.

Regarding correlation between work design and their productivity level of the studied nurses. Our present study demonstrated that, there was positive highly statistically significant correlation between work design and productivity.

Our results agree with Yusof, (2012) who revealed that, the importance of job design in boosting individual's productivity and performance have been discussed extensively in few studies (Dere, 2011). From the organizational aspect, job design plays crucial part in supporting the employees' work performance in achieving organizational relevant outcomes as it may directly or indirectly influences the manner; they perform their responsibilities and tasks (Ali \& Aroosiya, 2010). Hameed \& Amjad, (2009) add that by providing the needs of the employees 
such as with a conducive workplace could help in increasing their work productivity. Hence, the job design characteristics need to be assessed and restructured constantly in order to maintain an efficient work performance and productivity. this result not similar with Van Bogaert et al., (2014) who studied nursing unit teams' matter: Impact of unit-level nurse practice environment, nurse work characteristics, and burnout on nurse, Reported that, nurse practice environment dimensions reported to be unfavourable were associated with high workload, low decision opportunity, low social capital, and unfavourable outcome variables (productivity).

\section{Conclusion}

On the light of the current study, it can be concluded that a positive relation was found between staff nurses work design and their productivity level.

\section{Recommendations}

In the light of the finding reached from the present study, the following points are recommended

\section{For hospital administrator:}

1-The managers should understand the importance of job design as an essential component of work behavior among the workforce.

2- Nurse manager must optimize nurses' opportunities for personal and professional growth by creating a learning environment that enables reflective practice and shared accountability, demonstrate confidence in others by delegating effectively, coach, mentor, and guide and provide opportunities for the development of knowledge, skills.

3- The hospital administrators should provide nursing with resources that enable them to design the nursing work environment and care processes to reduce errors that affect their productivity

4- The nurse mangers must provide physically and psychologically supportive environment to nurses working that decrease the work problems, and increase level of their productivity.

5- Nurse managers must conduct periodic meetings with nurses to discuss their needs and do everything in their power to meet these needs to create a motivated environment and increase their productivity.

\section{For education:}

1-Conducting continuing education programs and training courses for nurse manager and their staff about: work design character, decision making involvement that can be used to increase staff nurses productivity.

\section{For further research:}

1-Reapplication of the study on the larger probability sample is highly recommended to achieve generalizable results.

2- Conduct study to investigate the factors that may affect work design and productivity.

3- Conduct study to identify strategies that increase work design characteristic level and its relation to nurses' productivity.

\section{References}

Abd Allah, R. (2011): The effect of models of organizing patient care on productivity at Shebin El Kom hospitals. Unpublished Master thesis, Faculty of Nursing, Menofia University. Egypt

Aithal S., \& PM S. (2016): Theory A for Optimizing Human Productivity.

Ali A. Y., Ali A., \& Adan A. (2013). Working conditions and employees' productivity in manufacturing companies in sub-Saharan African context: Case of Somalia. Educational Research International, 2(2), 67-78.

Ali H. \& Aroosiya M. (2010). Impact of job design on employees' performance (With Sp. school teachers in the Kalmunai zone). In Proceedings of the International Conference on Business 
\& Information, University of Kelaniya, Sri Lanka.

Asensio, S. (2012):"A method to design job rotation schedules to prevent work-related musculoskeletal disorders in repetitive work". International Journal of Production Research. 50 (24)7467-7478.

Bacon B, (2015): The Relationship between Work Complexity and Nurses' Participation in Decision Making in Hospitals.

Cascio W. \& Boudreau J. (2014). HR strategy: optimizing risks, optimizing rewards. Journal of Organizational Effectiveness: People and Performance.

Dere S., (2011). A diagnostic exploration of campus recreation using the work design questionnaire. Retrieved from https://digital.library.txstate.edu/handl e/10877/3341

Frederick P. (2015): The Work Design Questionnaire (WDQ Prepared by Morgeson.

Hameed A. \& Amjad S. (2009). Impact of office design on employee's productivity: a case study of banking organizations of Abbottabad, Pakistan.

Humphrey S. (2007). Integrating motivational, social, and contextual work design features: a meta-analytic summary and theoretical extension of the work design literature. Journal of applied psychology. 92(5):1332.

Jacksonvilla, U. (2014): Nurse Educator Jobs-Salary and Job Description and Outlook. Available at http://www. Jacksonvillaeu.com\resources\career\n urse-educator-job-salary-duties.
Latif A. (2018). Development and Psychometric Evaluation of Registered Nurses' Clinical Leadership Scale (RN-CLS) in Bangladesh (Doctoral dissertation, Prince of Songkla University).

Lazear E. \& Shaw K. (2007). Personnel economics: The economist's view of human resources. Journal of economic perspectives, 21(4), 91-114.

Morgeson F. (2019). Job and work analysis: Methods, research, and applications for human resource management. Sage Publications.

Olsen E. (2017): Work climate and the mediating role of workplace bullying related to job performance, job satisfaction, and work ability: A study among hospital nurses.

Parker S. (2014). Beyond motivation: Job and work design for development, health, ambidexterity, and more. Annual review of psychology, 65.

Rushdy F., \& Morsy S. (2016). Work design characteristics as perceived by nurse managers at Assiut University Hospital. IOSR Journal of Nursing and Health Science. Volume 5, Issue 1: PP 11-17.

Saber E. (2019). Impact of Job Characteristics on Nurses' Critical Psychological States at Assiut University Hospital. IOSR Journal of Nursing and Health Science (IOSRJNHS.; Volume 8, Issue 6: PP 17-24.

Yusof N. (2012). Job design and knowledge productivity: A conceptual framework. In Proceeding of the 19th International Business Information Management (IBIMA) Conference (Vol. 12, p. 13th). 